\title{
Typical hemolytic-uremic syndrome
}

INSERM

\section{Source}

INSERM. (1999). Orphanet: an online rare disease and orphan drug data base. Typical hemolytic-uremic syndrome. ORPHA:90038

Typical hemolytic-uremic syndrome (typical HUS) is a thrombotic microangiopathy characterized by mechanical hemolytic anemia, thrombocytopenia, and renal dysfunction that is usually associated with prodromal enteritis caused by Shigella dysentriae type 1 or E. Coli. 